\title{
IMPLEMENTASI E-COMMERCE MENGGUNAKAN CONTENT MANAGEMENT SYSTEM UNTUK PEMASARAN PRODUK PADA LUMI DISTRO DENGAN PENDEKATAN BUSINESS MODEL CANVAS
}

\author{
Gusti Adia Pamungkas Noor ${ }^{1)}$, Samsinar ${ }^{2)}$ \\ ${ }^{1}$ Sistem Informasi, Fakultas Teknologi Informasi, Universitas Budi Luhur \\ 1,2Jl. Raya Ciledug, Petukangan Utara, Kebayoran Lama, Jakarta Selatan 12260 \\ E-mail : gustiadia10@gmail.com ${ }^{1)}$, samsinar@budiluhur.ac.id ${ }^{2)}$
}

\begin{abstract}
Abstrak
Melihat perkembangan teknologi informasi yang sangat pesat, kebutuhan teknologi informasi telah menjadi kebutuhan utama untuk masyarakat. Salah satu aplikasi diinternet yang dibuat, untuk mendukung kebutuhan didalam dunia bisnis. Saat ini E-Commerce menjadi salah satu cara dalam proses peningkatan penjualan didalam suatu bisnis. Lumi Distro merupakan konsep distro yang menjual berbagai macam baju, jaket, celana, tas, sepatu dan berbagai macam aksesoris. Saat ini Lumi Distro hanya membuka toko fisik untuk melayani pelanggan sehingga penjualan hanya didapat dari pengunjung distro. Penelitian ini bertujuan untuk memberikan solusi alternatif kepada Lumi Distro dengan membuat website e-commerce agar penjualan semakin meningkat karena dapat diakses dimana saja dan kapan saja. Metode yang digunakan dalam pembuatan ecommerce ini menggunakan metode Beriorientasi Objek dan implementasi sistem e-commerce menggunakan Content Management System (CMS). Metode analisis yang digunakan ini menggunakan Business Model Canvas (BMC) bertujuan untuk strategi distro supaya penjualan dapat tersusun dengan baik dan maksimal. Dengan dibuatnya website e-commerce pada Lumi Distro akan menghasilkan peningkatan penjualan yang lebih maksimal dan pemasaran akan meluas.
\end{abstract}

Kata kunci: E-Commerce, Distro, Pemasaran, BMC

\section{PENDAHULUAN}

Melihat perkembangan teknologi informasi yang sangat pesat dengan pertumbuhan internet yang terus berkembang setiap harinya, kebutuhan teknologi informasi telah menjadi kebutuhan utama untuk masyarakat. Internet merupakan teknologi yang mempunyai cakupan yang sangat luas. Banyak aplikasi di internet yang di buat untuk mendukung kebutuhan pemerintahan, pendidikan, termasuk di dalam dunia bisnis. Semua aktifitas jual-beli produk fisik, digital, dan jasa sudah dibuatkan secara baik, dan mudah dengan adanya sistem e-Commerce.

E-Commerce adalah pertukaran barang dan jasa melalui sistem elektronik yang dilakukan oleh konsumen [1]. Dengan perkembangan teknologi informasi, kegiatan transaksi konvensional dapat dilakukan secara digital. Selama ini Lumi Distro menjalankan model e-Commerce Business to Business (B2B) dan Business to Consumer (B2C). Lumi Distro menjalankan transaksi bisnis antara Lumi Distro dengan pelaku bisnis yang lainnya dan melakukan penjualan ke konsumen secara langsung. Pembuatan website e-commerce Lumi Distro menggunakan Content Management System (CMS) yang merupakan perangkat lunak yang berfungsi untuk menambahkan atau memanipulasi isi dari situs web [2]. Dengan adanya website e-commerce dengan menggunakan CMS dapat memudahkan Lumi Distro untuk memasarkan produknya supaya semakin luas dan meningkatkan penjualan.

Lumi Distro merupakan salah satu toko yang menggunakan konsep distro yang menjual berbagai macam baju, jaket, kemeja, celana, tas, sendal dan berbagai macam aksesoris yang modern. Distro ini terlekat di Jl. Cipto Mangunkusumo No. 70 Ciledug, kota Tangerang. Lumi Distro sudah berdiri sejak tahun 2015, sampai saat ini Lumi Distro hanya membuka toko fisik untuk melayani pelanggan, belum mempunyai sistem penjualan online. Dengan sistem yang berjalan sekarang, masih terdapat kekurangan dalam media promosi untuk mengambangkan usahanya dan penjualan hanya di dapat dari pengunjung distro. Maka dari itu Lumi Distro membutuhkan penerapan website $e$ Commerce untuk meningkatkan penjualan yang lebih maksimal, sebagai media pemasaran supaya cakupan pasar lebih luas, dan dapat bersaing dengan distro online yang lain.

Pada penilitian ini penulis membuat model bisnis menggunakan Business Model Canvas (BMC). BMC dapat menjadi pendekatan yang mudah diimplementasikan oleh perusahaan dalam upaya melakukan evaluasi dan perubahan atau pembenahan terhadap model bisnis perusahaan. Lumi Distro menggunakan BMC supaya model bisnis yang baru dapat membantu kinerja yang lebih baik. Tujuan Lumi Distro menerapkan pendekatan 
BMC adalah untuk memformulasikan strategi pengembangan bisnis yang tepat dan dapat diterapkan bagi Lumi Distro dalam pengembangan usaha jangka panjang.

\section{METODE PENELITIAN}

\subsection{Kerangka Pemikiran}

Gambar 1 merupakan kerangka pemikiran yang sudah dibuat oleh peneliti yaitu:

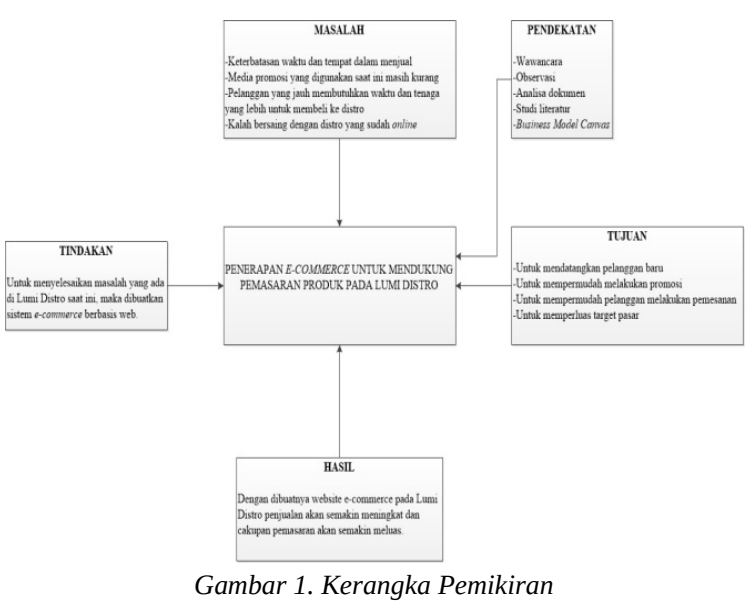

\subsection{Metode Pengumpulan Data}

Untuk menyelesaikan masalah yang ada di Lumi Distro metode yang dilakukan oleh peneliti guna mendapatkan data yang berjalan saat ini, yaitu: a. Wawancara

Pada kegatan ini peneliti mengajukan pertanyaan secara lisan kepada pemilik Lumi Distro. Wawancara dilakukan punulis untuk mendapatkan bagaimana arus proses bisnis penjualan pada Lumi Distro.

\section{b. Observasi}

Pada kegiatan ini peneliti melihat pengamatan langsung dalam proses penjualan, dengan bertujuan mendapatkan data yang lebih maksimal.

\section{c. Analisa Dokumen}

Pada kegiatan ini peneliti mengumpulkan dokumen yang ada di Lumi Distro seperti nota dan laporan.

\section{d. Studi Literatur}

Penelitian studi literatur ini dilakukan guna mendapatkan referensi yang sama dengan permasalahan yang sedang terjadi pada Lumi Distro. Studi ini didapatkan dari berbagai jurnal untuk dijadikan acuan pada kegiatan penilitian diantaranya:

Penelitian yang dilakukan oleh Dippos Manulang, Leon Andretti Abdillah dan Kurniawan berjudul "Sistem Informasi Penjualan Online (ECommerce) Menggunakan CMS Wordpress Pada
Toko Soraya Shop Dengan Menerapkan Metode RAD)” yang dipublikasian pada jurnal SHaP-SITI [3]. Penjualan Soraya Shop ini masih menjadi masalah untuk mendapatkan tujuan perusahaan, dikarenakan penjuala dan sistem transaksi masih secara manual. Dengan adanya masalah tersebut, Soraya Shop menemukan solusi untuk menyelesaikan masalah yang ada dengan membuat Wordpress dan RAD. Tujuann Soraya Shop menggunakan Wordpress untuk meningkatkan loyalitas pelanggan agar bertahan, penjualan yang semakin meningkat, pemasaran yang semakin meluas dan menjaga hubungan pelanggan agar terciptanya kesetiaan pelanggan terhadap Soraya Shop.

Penelitian yang dilakukan oleh Himawan, Asep Saefullah dan Sugeng Santoso berjudul "Analisa dan Perancangan Sistem Informasi Penjualan Online (ECommerce) pada CV Selaras Batik Menggunakan Analisis Deskriptif” yang dipublikasikan pada jurnal Scientific Journal Of Informatics [1]. Permasalahan yang terjadi di CV Selaras Batik masih mengutakan metode penjualan yang masih tradisional. Berkaitan dengan masalah tersebut, CV Selaras Batik mengharapkan menggunakan aplikasi e-Commerce untuk dapat membuat penjualan semakin meningkat dan menjadi sarana infromasi kepada pelanggan.

Penelitian yang dilakukan oleh Mawardi Bagindo, Bunasor Sanim dan Teguh Imam Saptono berjudul "Model Bisnis Ekowisata di Taman Nasional Laut Bunaken dengan Metode Pendekatan Business Model Canvas” yang dipublikasikan pada jurnal Manajemen Pengembangan Industri Kecil Menengah [4]. Saat ini pengelolaan yang ada di Indonesia adalah pengelolaan berbasis ekosistem, spesies, pemberbadayaan masyarakat maupun penetapan Taman Nasional. Model ini belum mampu mengatasi masalah secara optimal. Pendekatan yang dibuat untuk suatu pengembangan adalah dengan menggunakan model bisnis. Pendekatan model bisnis salah satu faktor untuk sukses dari suatu organisasi. Pendekatan model bisnis ini menggunaan Business Model Canvas. Tujuan model bisnis BMC ini untuk memperbaiki model bisnis suatu organisasi yang dijadikan analisa model bisnis yang lebih maksimal untuk pengembangan TNL Bunaken.

\subsection{Teknik Analisis Data Dan Penggunaan Tools}

a. Analisis Proses Bisnis

Analisis proses bisnis dilakukan peneliti dengan cara menguraikan proses bisnis dalam lingkup penelitian, digambarkan menggunakan Activity Diagram.

\section{b. Analisis Masalah}

Analisis masalah yang dilakukan oleh peneliti adalah wawancara dan observasi. Kegiatan ini guna mendapatkan permasalahan yang terjadi pada Lumi 
Distro, lalu dilanjuti dengan menguraikan sebabakibat yang terjadi dengan Lumi Distro

c. Analisis Kebutuhan

Setelah mendapatkan permasalahan yang ada pada Lumi Distro. Lalu permasalahan itu akan dibuatkan solusi dengan cara mencari kebutuhan apa saja yang dibutuhkan, kemudian digambarkan dengan Use Case Diagram, Class Diagram.

\subsection{Metode Analisis}

Business Model Canvas adalah metode analisis yang dipakai dalam melakukan penelitian ini. Karena, menggunakan BMC untuk mendapatkan model bisnis yang baru agar menghasilkan model bisnis yang lebih maksimal. Diharapkan dengan adanya metode ini dapat membantu bagaimana cara memetakan model bisnis pada suatu organisasi yang sedang dianalisis menjadi pengembangan strategi penjualan model bisnis yang lebih baik bagi Lumi Distro. Lumi Distro juga memanfaatkan Search Engine Optimization (SEO) guna meningkatkan ranking web pada mesin pencarian bertujuan untuk pemasaran agar mudah dicari oleh calon pelanggan. Lumi Distro hanya menggunakan SEO on Page. Dalam SEO on Page Lumi distro akan menggunakan webmaster pada google agar terdaftar di google dan memakai plugin YoastSEO.

\section{HASIL DAN PEMBAHASAN}

\subsection{Businness Model Canvas}

Business Model Canvas alat untuk memodifikasi model bisnis baru pada perusahaan untuk membuat strategi yang lebih tepat [5]. Didalam BMC terdapat 9 elemen. Elemen-elemen ini membantu memudahkan perusahaan untuk menemukan aktivitas baru yang dapat dilakukan untuk pengembangan strategi bisnisnya. Pada gambar 2. menjelaskan 9 elemen yang berada pada Lumi Distro diantaranya:

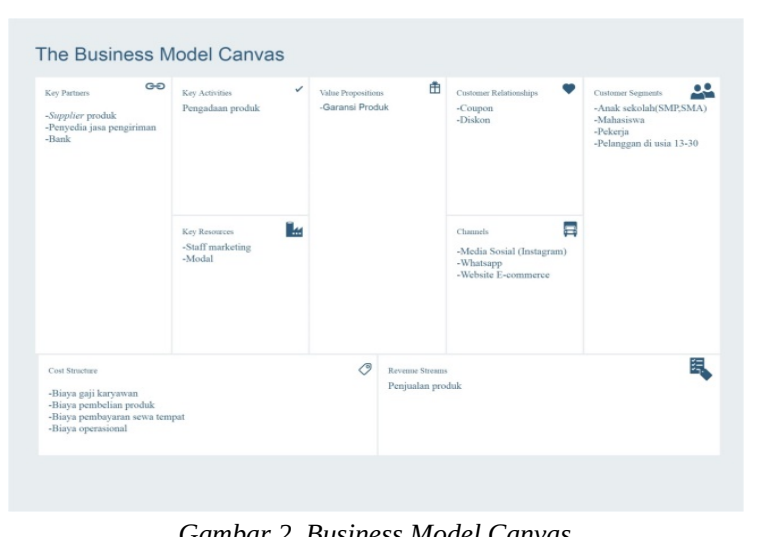

Gambar 2. Business Model Canvas

\section{a. Customer Segments}

Sasaran yang dituju adalah laki-laki yang berusia mulai dari usia 13-30 tahun karena produkproduk yang dijual oleh Lumi Distro memang kushus laki-laki dan untuk anak-anak muda. Anakanak sekolah seperti anak SMP dan SMA menjadi sasaran Lumi Distro, begitu pula mahasiswa dan pekerja menjadi sasaran penjualan.

b. Value Propositions

Kelebihan yang diberikan Lumi Distro produk yang dijual bergaransi, produk berasal dari brand ternama, desain produk yang modern, mengikuti perkembangan fashion, dan harga yang di jual di Lumi Distro lebih murah.

c. Channels

Intstagram menjadi media yang digunankan oleh Lumi Distro untuk menarik calon pelanggan agar membeli produk tersebut. Lumi Distro menggunakan Whatsapp sebagai media komunikasi untuk melayani pelanggan secara langsung. Dan dapat memesan produk langsung melalui website $e$ commerce yang telah dibuat.

d. Customers Relationship

Cara Lumi Distro guna mendapatkan calon pelanggan yang baru dan mempertahankan pelanggan yang lama untuk memilih dan membeli produk di Lumi Distro dengan cara memberikan informasi promo-promo seperti coupon. Setiap akhir bulan Lumi Distro cuci gudang seperti produkproduk di diskon hingga 50\%.

e. Revenue Stream

Pada Lumi Distro produk utama yang dijual adalah baju, jaket, celana, tas, sandal dan aksesoris. Dengan adanya penjualan produk tersebut akan membuat sumber pendapatan utama pada Lumi Distro.

f. Key Activities

Cara penjual mendapatkan key activities pada Lumi Distro adalah pengadaan produk seperti baju, kemeja, jaket, celana, tas, sandal dan aksesoris ke supplier.

g. Key Resource

Lumi Distro membutuhkan sumber daya agar bisnisnya dapat berjalan dengan baik dan lancar dibutuhkan seperti staff marketing agar penjualan produk lebih maksimal dan modal untuk berjalannya bisnis.

h. Key Partners

Lumi Distro bekerja sama dengan pihak yang terlibat untuk membantu berjalannya bisnis seperti supplier baju, kemeja, jaket, celana, tas, sandal, dan aksesoris yang memasok produk di distro. Penyedia jasa pengiriman sebagai pihak yang melakukan pengiriman produk. Bank sebagai pihak untuk melakukan transaksi pembayaran.

i. Cost Structure 
Biaya yang dilakukan oleh Lumi Distro yaitu biaya pembelian produk ke supplier baju, kemeja, jaket, celana, tas, sandal, dan aksesoris, lalu biaya gaji karyawan setiap bulannya, biaya sewa tempat setiap tahunnya, dan biaya operasional.

\subsection{Proses Bisnis}

Penggambaran urutan aktifitas dalam sebuah proses bisnis adalah sebagai berikut:

a. Proses Pemesanan

Gambar 3 dan Gambar 4 menjelaskan bagaimana pelanggan melakukan pemesanan melalui website Lumi Distro. Pelanggan memilih produk yang akan dipesan, jika sudah memilih pelanggan mengklik produk yang ingin dipesan, setelah itu pelanggan dapat melihat informasi lengkap produk tersebut. Pelanggan memilih ukuran dan jumlah yang akan dipesan. Kemudian pelanggan mengklik tombol add to cart dan produk tersebut akan masuk ke keranjang belanja, lalu pelanggan mengklik view cart untuk melihat produk yang dipesan sudaghsesuai pesanan. Jika pelanggan masih ingin berbelanja, pelanggan memilih produk yang lain, jika tidak pelanggan dapat mengklik proceed to checkout untuk proses berikutnya. Jika pelanggan belum login, pelanggan tidak akan bisa melanjutkan proses konfirmasi pesanan dan harus login terlebih dahulu. Setelah login pelanggan melakukan konfirmasi pesanan yang berada di halaman checkout. Kemudian pelanggan mengisi form yang sesuai untuk data pengiriman, dan memilih jasa pengiriman, setelah mengisi form pelanggan mengetahui total yang harus dibayar dan pelanggan memilih bank untuk melakukan pembayaran. Setelah itu pelanggan mengklik tombol place order, lalu pelanggan akan mendapatkan informasi detail pesanan serta nomor rekening bank Lumi Distro.

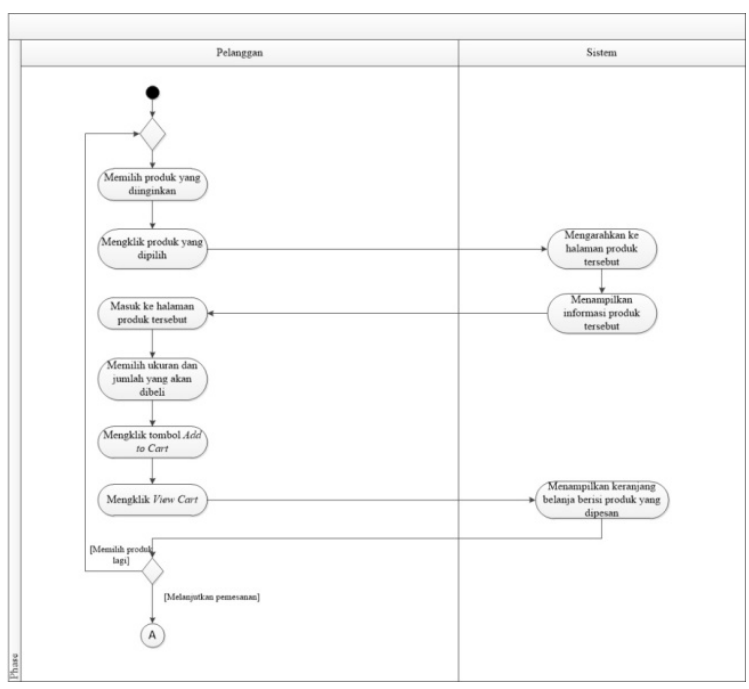

Gambar 3. Activity Diagram Proses Pemesanan bag. 1

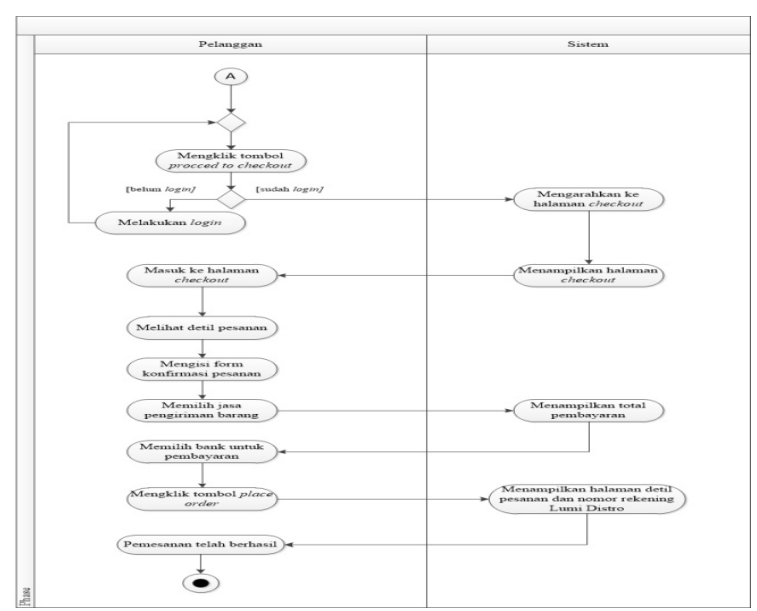

Gambar 4. Activity Diagram Proses Pemesanan bag. 2

b. Proses Konfirmasi Pembayaran

Gambar 5 menjelaskan bagaimana pembayaran dilakukan dengan cara mengirim uang melalui ATM atau Mobile Banking ke nomor rekening Lumi Distro. Setelah pelanggan melaukan pembayaran, pelanggan melakukan konfirmasi pembayaran yang berada di website. Pelanggan memilih menu konfirmasi pembayaran, kemudian pelanggan mengisi form konfirmasi pembayaran. Setelah mengisi form pelangan mengklik tombol kirim, lalu pelanggan akan mendapatkan informasi bahwa konfirmasi pembayaran berhasil dikirim. Admin website akan memverikasi setiap konfirmasi pembayaran yang masuk melalui Caldera Forms konfirmasi pembayaran. Jika pembayaran diterima, status pesanan pelanggan akan diubah dari on-hold menjadi processing dan pesanan segera dikirim, jika pembatan belum diterima dalam 1x24 jam, maka admin akan membatalkan pesanan tersebut.

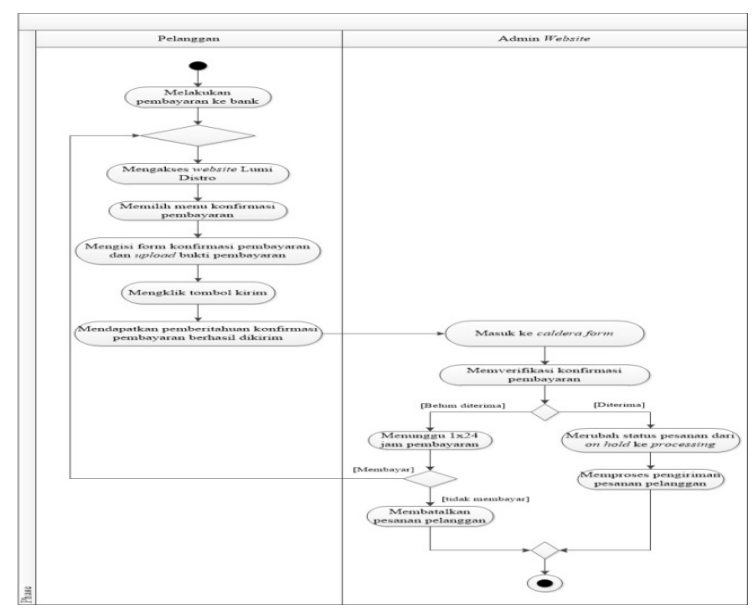

Gambar 5. Activity Diagram Konfirmasi Pembayaran

c. Proses Pengiriman

Gambar 6 menjelaskan bagaimana Admin masuk ke halaman backend website, lalu pilih menu 
woocommerce, setelah itu klik menu orders. Pada halaman orders admin mengecek pesanan pelanggan yang sudah membayar untuk mencetak label pengiriman. Lalu staff distro akan menyiapkan pesanan sesuai dengan label pengiriman yang sudah dicetak dan membungkus pesanan untuk di kirim melalui jasa pengiriman. Staff distro membawa pesanan tersebut untuk dikirim melalui jasa pengiriman. Staff distro membayar total biaya pengiriman pesanan, setelah itu staff distro akan mendapatkan nomor resi yang akan di berikan ke admin. Admin memasukan nomor resi melalui notes ke pesanan pelanggan, lalu mengklik tombol update, dan nomor resi akan masuk di my account orders pelanggan yang sudah dikirim produknya.

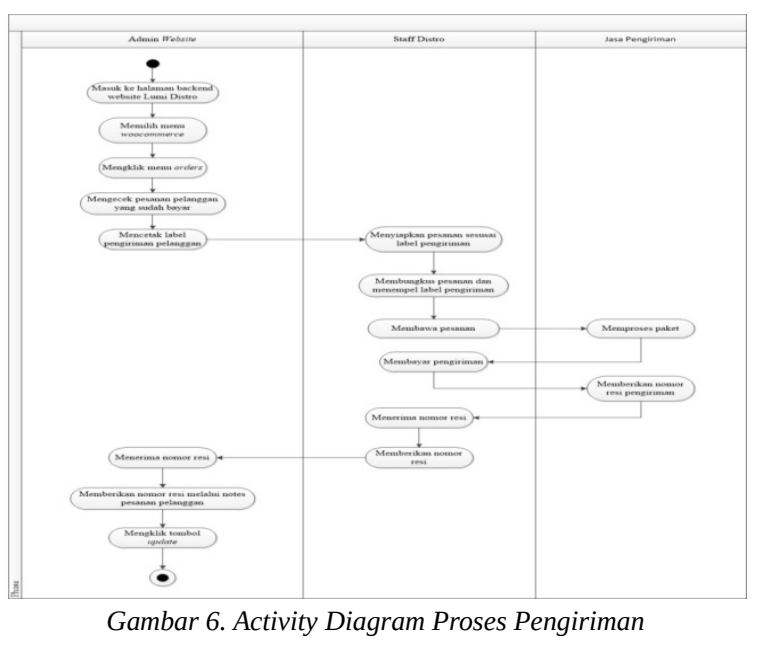

\subsection{Use Case Diagram}

Use case diagram membantu membuat pemodelan untuk kelakukan sistem informasi yang akan dibuat [6]. Penjelasan use case diagram yang dbuat adalah sebagai berikut:

a. Use Case Diagram Master

Gambar 7 yaitu Use Case Diagram Master terdapat usecase untuk pelanggan yang terdiri dari registrasi akun dan login. Use Case Diagram Master untuk admin website terdiri dari use case login, tambah produk, tambah kategori, tambah tags, tambah atribut, dan tambah jasa pengiriman.
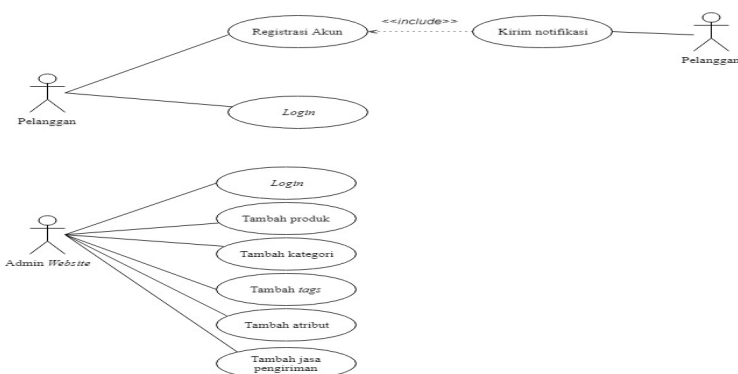

Gambar 7. Use Case Diagram Master b. Use Case Diagram Transaksi Pelanggan

Gambar 8 yaitu Use Case Diagram transaksi pelanggan terdapat use case orders produk, cart, checkout, lihat invoice, input konfirmasi pembayaran, dan input refund.

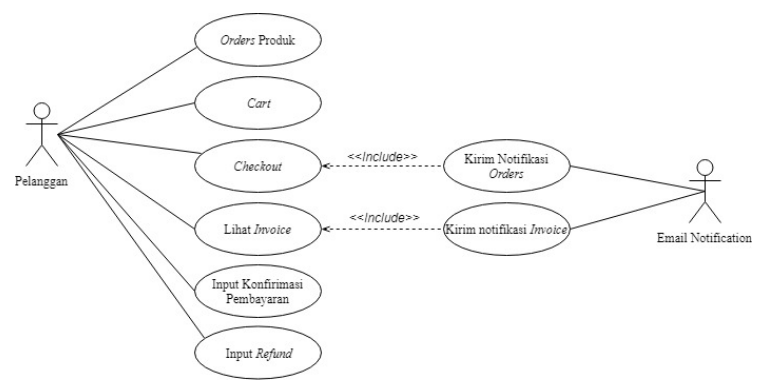

Gambar 8. Use Case Diagram Transaksi Pelanggan

c. Use Case Diagram Transaksi Admin Website

Gambar 9 yaitu Use Case Diagram transaksi admin website terdapat use case verifikasi konfirmasi pembayaran, verifikasi refund, dan cetak invoice.

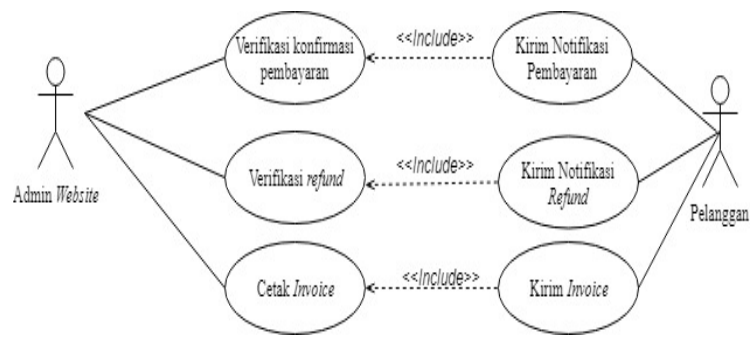

Gambar 9. Use Case Diagram Transaksi Admin Website

d. Use Case Diagram Laporan

Gambar 10 yaitu Use Case Diagram laporan terdapat use case laporan pemesanan, laporan penjualan, laporan pengriman, laporan refund, laporan produk terlaris.

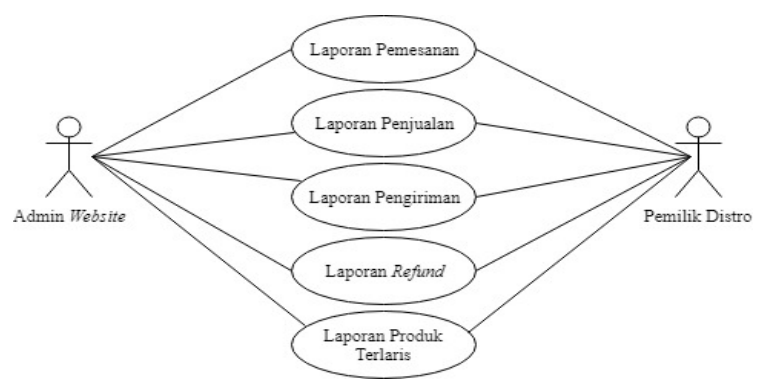

Gambar 10. Use Case Diagram Laporan

\subsection{Class Diagram}

Class Diagram merupakan hubungan antar tiap-tiap kelas dan penjelasan detail didalam model desain dari suatu sistem [6]. Pada gambar 11 menjelaskan class diagram yang telah di buat yaitu sebagai berikut: 


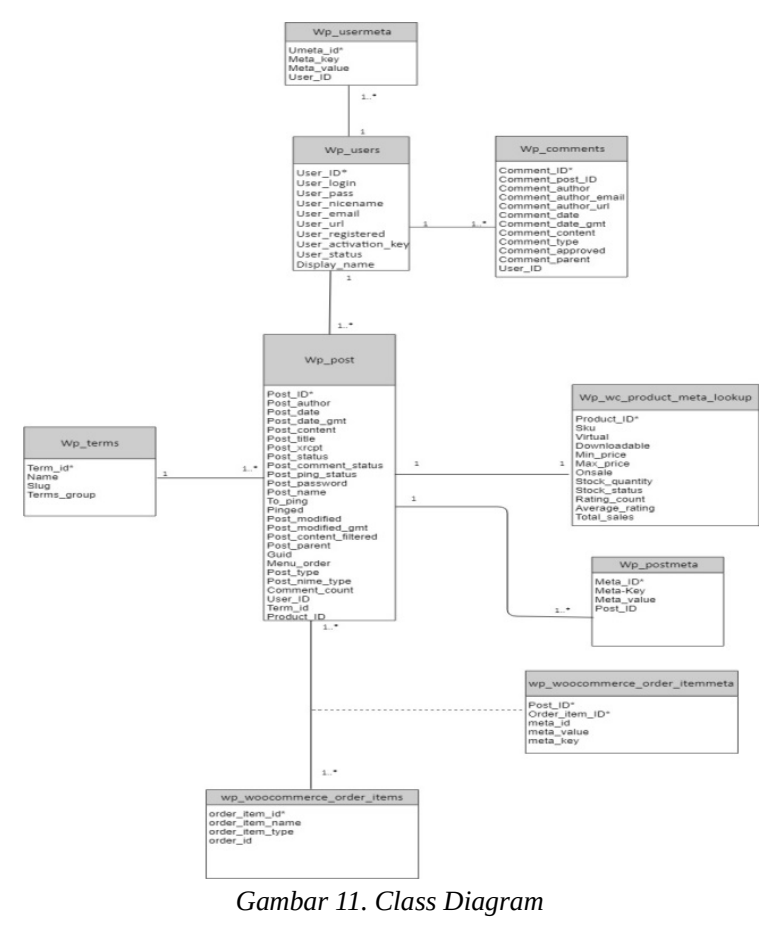

\subsection{Tampilan Website}

a. Tampilan Website Home

Pada gambar 12 tampilan home pelanggan dapat dilihat sebagai berikut:

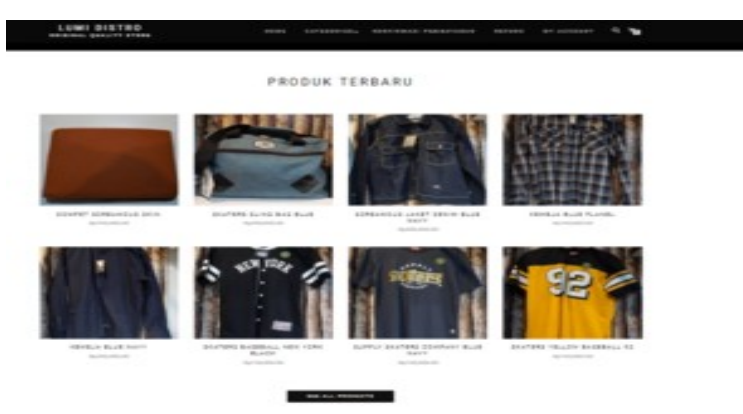

Gambar 12. Tampilan Website Home

b. Tampilan Website Orders Produk

Pada gambar 13 tampilan orders produk pelanggan dapat memilik size dan jumlah yang ingin dipesan setelah itu pelanggan klik add to cart untuk memesan produk.

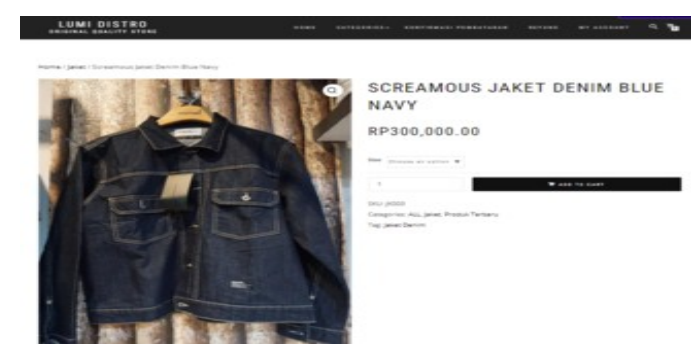

Gambar 13. Tampilan Website Orders Produk c. Tampilan Website Cart

Pada gambar 14 tampilan cart merupakan keranjang belanja yang berisikan produk yang telah dipesan.

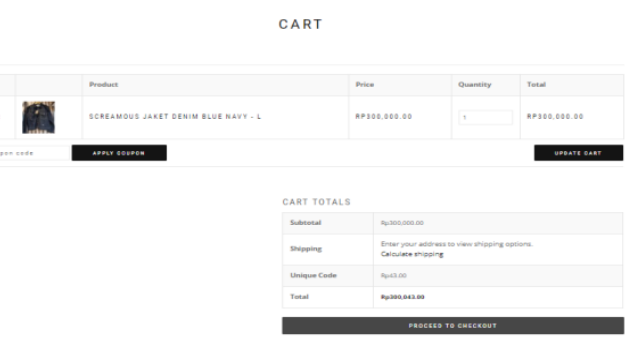

Gambar 14. Tampilan Website Cart

d. Tampilan Website Konfirmasi Pembayaran

Pada gambar 15 tampilan konfirmasi pembayaran dilakukan setelah pelanggan melakukan pembayaran lalu mengisi form yang berada di menu konfirmasi pembayaran untuk melanjutkan proses pemesanan.
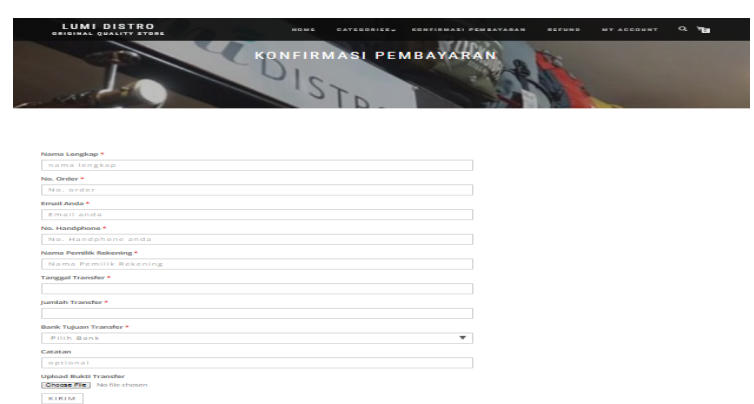

Gambar 15. Tampilan Website Konfirmasi Pembayaran

e. Tampilan Website Checkout

Pada gambar 16 tampilan checkout pelanggan melakukan konfirmasi pesanan dengan mengisi form yang ada untuk mengetahui total yang harus dibayar dan memilih jasa pengiriman.

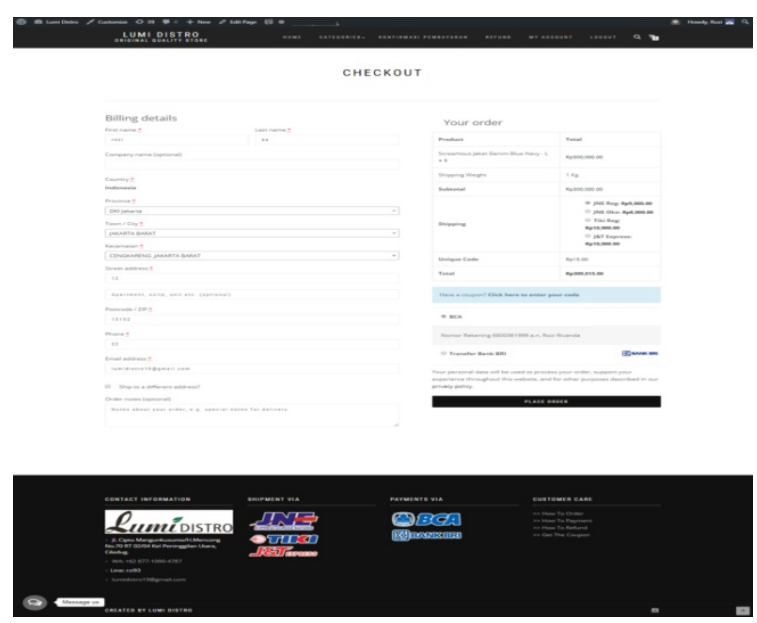

Gambar 16. Tampilan Website Checkout 
f. Tampilan Laporan Penjualan

Pada gambar 17 tampilan laporan penjualan yang dibuat oleh admin website setiap bulan.

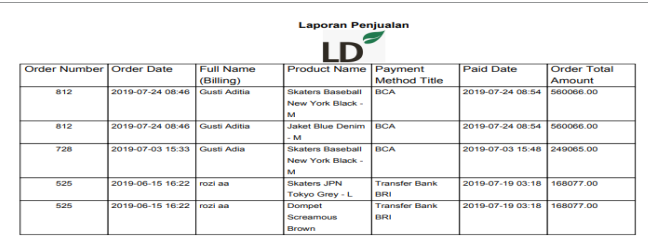

Gambar 17. Tampilan Laporan Penjualan

\subsection{Strategi Search Engine Optimizayion (SEO)}

SEO merupakan upaya yang kita lakukan untuk meningkatkan ranking website pada mesin pencari [7]. Dalam membuat strategi SEO untuk penerapan e-commerce pada Lumi Distro, peniliti hanya menggunakan strategi SEO on Page. Lumi Distro mengoptimalkan SEO on Page dengan menggunakan plugins Yoast SEO dan mengatur isi konten pada halaman website. Berikut langkahlangkahnya:

a. Menentukan Kalimat Pencarian Dasar

Gambar 18 pencarian kata kunci merupakan tahap awal dalam penerapan SEO on Page, kata kunci yang relevan dengan distro dan produk yang dijual merupakan dasar dalam pencarian kata kunci. Keywords atau kata kunci merupakan sebuah kata atau kalimat yang disusun untuk mencari website atau informasi yang terdapat di internet. Kata kunci yang dipilih difokuskan pada main content website, dimana main content tersebut ada pada detail produk atau informasi produk yang dijual.

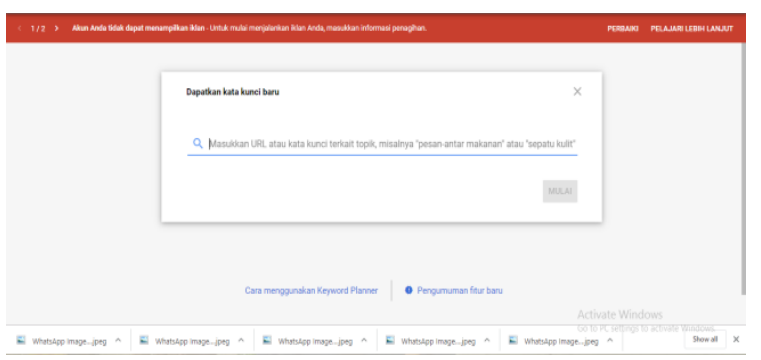

Gambar 18. Menentukan Kalimat Pencarian dasar

b. Penempatan Kata Kunci

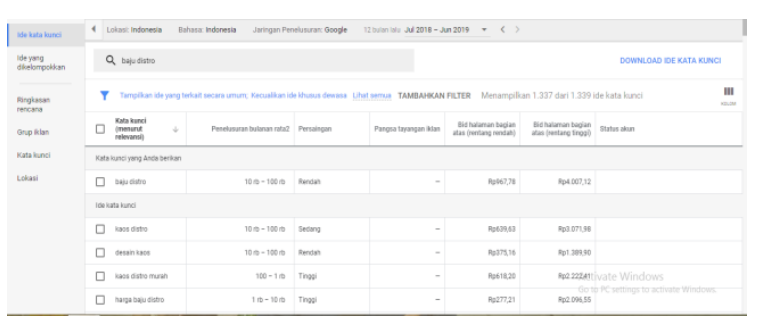

Gambar 19. Penempatan Kata Kunci
Gambar 19 setelah penentuan kata kunci dasar, selanjutnya adalah pencarian kata kunci menggunakan keywords tool.

c. Menggunakan Plugin Yoast SEO

Gambar 20 Plugin Yoast SEO merupakan sebuah plugin yang dapat mempermudah dan membantu website untuk terindex pada Google. Pada Yoast SEO admin dapat mengambil sitemaps yang berada di Yoast SEO lalu memasukan sitemaps pada Google webmaster search console agar terindex oleh Google. Selain itu Yoast SEO dapat mengatur keyword yang akan terindex ke Google.

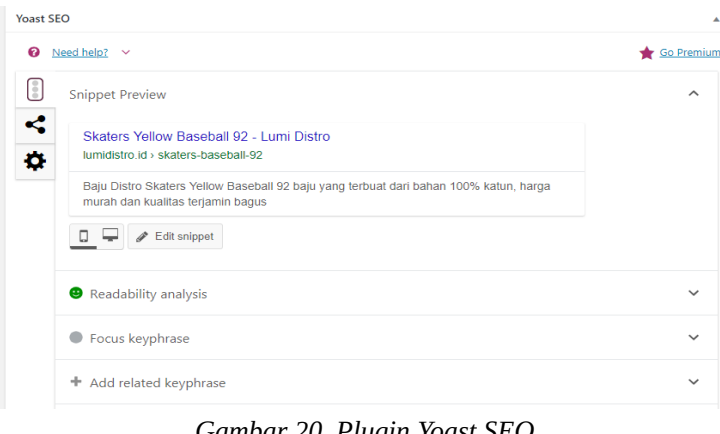

d. Hasil Penerapan SEO

Gambar 21 dan Gambar 22 hasil penerapan SEO yang telah diterapkan pada website Lumi Distro sebagai berikut:

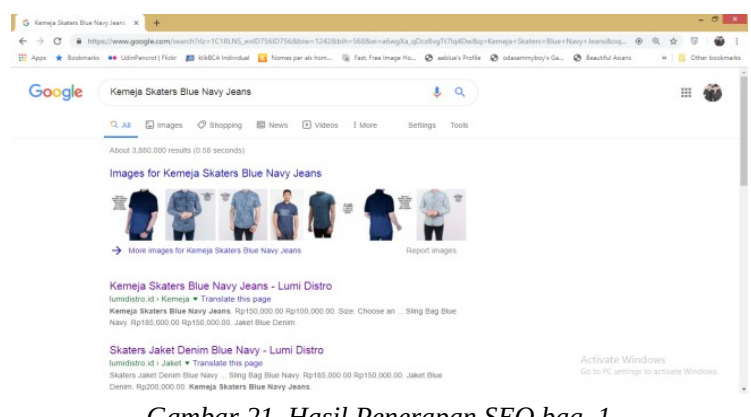

Gambar 21. Hasil Penerapan SEO bag. 1

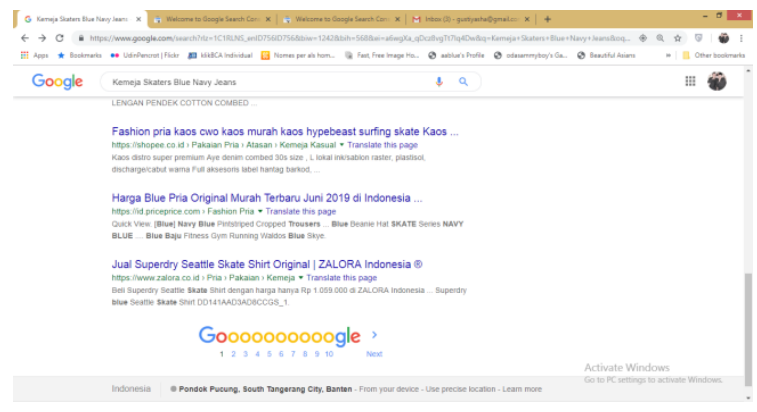

Gambar 22. Hasil Penerapan SEO bag. 2

\subsection{Strategi Marketing}

Gambar 21 strategi pemasaran Lumi Distro menggunakan media sosial Instagram. Nantinya 
akan diarahkan ke halaman website e-commerce Lumi Distro untuk melakukan pemesanan hingga transaksi. Instagram hanya sebatas tempat promosi.

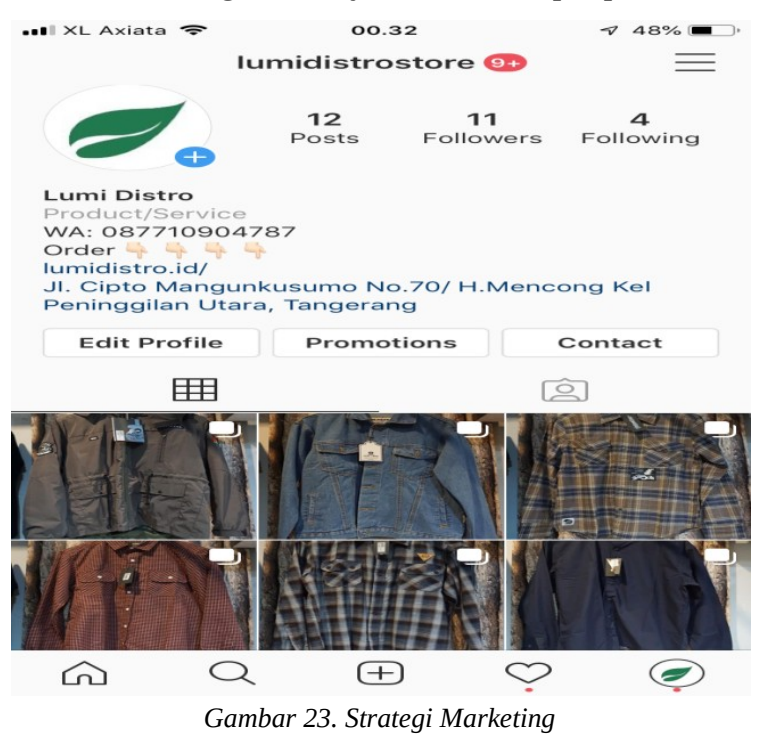

\section{KESIMPULAN}

Setelah mempelajari masalah yang didapatkan dan mencari solusi dari masalah yang ada pada Lumi Distro, maka terdapat kesimpulan sebagai berikut:

a. Dengan adanya fitur cart pada website $e$ commerce Lumi Distro, pelanggan dengan mudah dapat memesan produk kapan saja dan dimana saja sehingga membuat penjualan Lumi Distro akan menjadi lebih maksimal.

b. Dengan adanya fitur Instagram Lumi Distro dapat mempromosikan produknya lalu tersambung dengan website yang sudah dibuat. Selain itu Lumi Distro menggunakan fitur Yoast SEO untuk terindex oleh Google sehingga membuat jangkauan pasar semakin luas.

c. Dengan adanya fitur pemesanan seperti cart dan checkout pada website Lumi Distro, pelanggan dapat memesan melalui website tanpa harus datang langsung ke distro.

d. Dengan adanya fitur SEO website Lumi Distro dapat bersaing dengan distro yang sudah online sehingga penjualan produk lebih unggul.

\section{DAFTAR PUSTAKA}

[1] H. Himawan, A. Saefullah and S.Santoso, "Analisa dan Perancangan Sistem Informasi Penjualan Online (E-Commerce) pada CV Selaras Batik Menggunakan Analisis Deskriptif," Scientific Journal of Informatics, 1(1), pp. 53-63, 2014.
[2] A. Wahana, "Rancang Bangun Marketplace Produk Kewirausahaan Mahasiswa UPY Berbasis Content Management System," Jurnal Dinamika Informatika, 7(1), pp. 73-81, 2018.

[3] D. Manulang, L. A. Abdillah and Kurniawan, "Sistem Informasi Penjualan Online (E-Commerce) Menggunakan CMS Wordpress pada Toko Soraya Shop dengan Menerapkan Metode RAD," SHaPSITI, pp. 7-12, 2017.

[4] M. Bagindo, B. Sanim, and I. T. Saptono, "Model Bisnis Ekowisata di Taman Nasional Laut Bunaken dengan Pendekatan Business Model Canvas," Jurnal Manajemen Pengembangan Industri Kecil Menengah, 11(1), pp. 80-88, 2016.

[5] A. Jackson and D. Harjanti, "Evaluasi Dan Perancangan Model Bisnis Berdasarkan Business Model Canvas," Agora, 3(1), pp. 8-16, 2015.

[6] A. Hendini, "Pemodelan UML sistem informasi Monitoring Penjualan dan Stok Barang (Studi Kasus: Distro Zhezha Pontianak)," Jurnal Khatulistiwa Informatika, IV(2), pp. 107-116, 2016.

[7] U. Rahardja, R. I. T. Wijaya and E. N. Dewi, "Peningkatan Rank Alexa Menggunakan Metode Seo Untuk Meningkatkan Web Visitor Pada Official Site Ilearning Plus," Jurnal CCIT, 10(1), pp. 1-15, 2016.H. Himawan, A. Saefullah and S.Santoso, "Analisa dan Perancangan Sistem Informasi Penjualan Online (E-Commerce) pada CV Selaras Batik Menggunakan Analisis Deskriptif," Scientific Journal of Informatics, 1(1), pp. 53-63, 2014. 